\title{
Giving Thanks at Thanksgiving Point
}

\author{
Kari Ross Nelson
}

Before the COVID-19 pandemic, self-care was trending in the museum field. In the thick of the pandemic, blogs and webinars from museum-related professional associations featured discussions around the topic. ${ }^{1}$ Meditation, 'unplugging', time outdoors, and exercise were commonly discussed practices. However, the practice of gratitude was seldom mentioned. Academic studies have shown that gratitude can make people happier, improve their relationships, and potentially counteract depression and suicidal thoughts. A 2015 study demonstrated the clinical benefits of gratitude. The 293 participants were randomly assigned to one of three interventions. All received counselling services. Members of one group were also instructed to write a letter of gratitude to another person each week. At the conclusion of the interventions, participants in the gratitude cohort reported significantly better mental health (Wong et al. 2018). Current studies suggest the benefits of gratitude extend to physical health as well (Jans-Beken et al. 2019). While expressing gratitude will not solve every pandemic challenge, we at Thanksgiving Point found tapping into the origins of our name to be a refreshing response to coping with difficulties and to positively affect staff satisfaction, visitor loyalties, and fundraising.

Thanksgiving Point Institute is a farm, garden, and museum complex in Lehi, Utah, USA, approximately $45 \mathrm{~km}$ south of Salt Lake City. When Alan Ashton, co-founder of WordPerfect, gifted a large parcel of farmland to his wife Karen for Valentine's Day in 1995, they intended to build a public garden and farm experience with a mission to 'draw upon the natural world to cultivate transformative family learning'. The name Thanksgiving Point was chosen to show gratitude to the community that supported the couple as they grew their business, as well as to their Creator.

Thanksgiving Point has grown to include five venues, hosting over two million visitors annually. Museums and gardens in the USA typically generate approximately 40 per cent of their revenue from memberships and admissions, gift shop and food sales, and venue rentals - in other words, from visitors. Thanksgiving Point typically earned 80-85 per cent of its revenue from these sources before grants, donations, and sponsorships rounded out the budget. Yet on 16 March 2020, COVID-19 concerns mandated closure of all venues. No visitors meant an immediate loss of 80-85 per cent revenue, and just as stinging, threatened our ability to do jobs we love.

As the song lyrics say (Joni Mitchell or Cinderella, depending on your generation), 'you don't know what you've got 'till it's gone'. With uncertainty about when Thanksgiving Point might reopen, this sentiment unsettled employees. Then founders Alan and Karen Ashton offered to subsidize the payroll in the short term. This gift, along with the US government's Paycheck Protection Program, kept people working, allowing us to curate online content and to plan for a measured yet strong reopening. It also initiated a practice of gratitude on multiple fronts.

\section{Giving Thanks}

Without our founders' gift, many of us would have been furloughed or laid off. When a few employees came to managers with letters of thanks, asking that they be delivered to the Ashtons, leaders invited anyone who wished to submit such letters to do so. Dozens of employees wrote letters, which were delivered in a custom box crafted by our exhibits manager. 
As employees wrote about the personal impact of the gift, they expressed enthusiasm for their work:

I can't thank you enough for your generosity and selflessness. Without my salary being paid, we would struggle to afford our mortgage, groceries, and other expenses. I am forever indebted to you both for helping us survive this difficult time. I can't wait to get back to work and put smiles on our guests' faces again.

We are all incredibly grateful for your kind hearts and generosity! Working at Thanksgiving Point is such a joy; I love the camaraderie and the culture that has been built. Thank you for setting a gracious example for us.

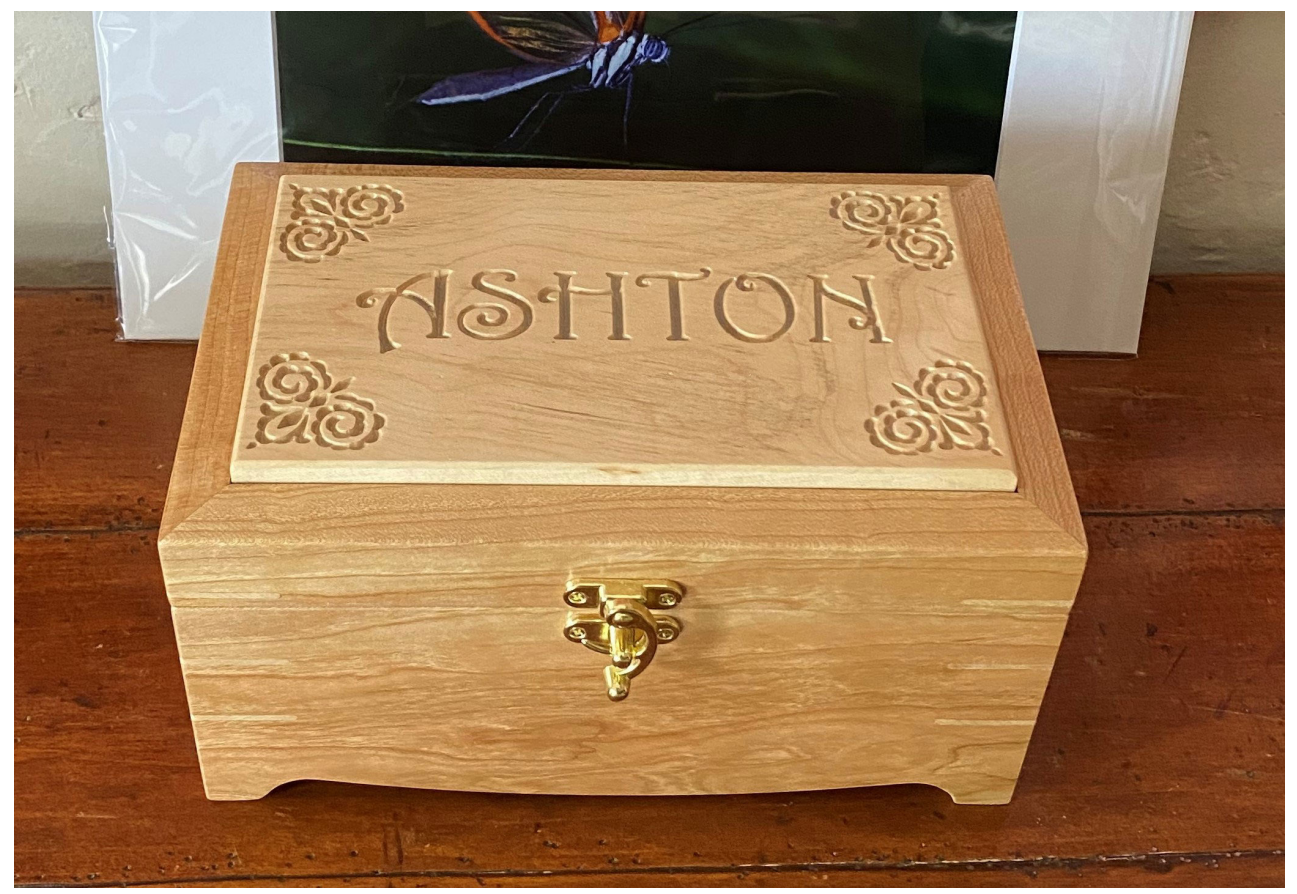

Figure 1. Hand-crafted box for letters of thanks.

\section{Sometimes It's Nice to Be on the Receiving End}

Gratitude emerged among visitors as well. In Utah, restrictions on public places were loosened in mid-May, and we prepared for reopening. Activities included a survey to ascertain our community's feelings and needs so that we could make reopening safe and comfortable. In open-ended responses, visitors expressed thanks for our presence, for the opportunities provided by our venues, and for our concern for their well-being.

We have truly missed attending the beautiful Tulip Festival, which has been a tradition for our family since we moved here. We are so grateful for the service and inspiration you provide through your venues and programs. We want all your staff to stay safe. We sure look forward to being able to visit again.

Thank you for all the steps you are taking to keep people safe. We love Thanksgiving Point; we used to go on a weekly basis. That being said we won't be visiting until COVID-19 has died down. Just for the safety for our family. We miss you all and are grateful for all you have done for us online during this time! 
We need you to continue to be there so we can feel a sense of normalcy again and have a place to refresh and restore our emotions. Thank you for being such a great asset to our community, state and country!

Some responses were shared in an all-employee email. Being on the receiving end of this gratitude provided much-needed encouragement.

\section{Giving Back}

Early May, the first peak of the pandemic in the USA, was also high season for tulips in Ashton Gardens at Thanksgiving Point. While the gardens were closed to visitors, staff harvested the tulips and delivered bouquets to nursing staff at local hospitals as a thank you for risking their health to serve others.

Also in early May, the Giving Tuesday movement (givingtuesday.org) designated a special edition of the day: Giving Tuesday Now. Thanksgiving Point's development team invited employees to give back and/or use their social media channels to invite others to donate. The fundraising goal was $\$ 3,000$ US; employees and friends gave nine times that amount.

\section{Why This Matters}

Research professor and author Brené Brown lists 'practicing gratitude and celebrating milestones and victories' as a characteristic of 'daring leadership' (Brown 2018: 83). How can leaders foster this practice in their museums and among staff? Here are some ideas:

1. Do not leave gratitude unsaid. In addition to conventional recognition programs, consider inviting employees to occasionally pause their work and recognize each other's accomplishments. Sharing accomplishments can increase employee engagement, satisfaction, and retention, boosting the outlook and well-being of both givers and receivers.

2. Don't leave thanks solely to the development department. Make sure employees have opportunities - such as letter writing campaigns, suggestion boxes or social media campaigns - to give back to the organization or the community. At the same time, do be sensitive to furloughed employees. Such opportunities might not be appropriate for them, but they could be thanked for their patience and sacrifices.

3. Perhaps start a meeting with a round-robin activity where attendees can say something they're grateful for. This might include the technologies that have allowed them to maintain contact safely with each other and visitors; professional organizations where we can share best practices and lived experiences with reopening; a pay cheque; a clear blue sky. At the same time, don't coerce anyone to participate. Gratitude needs to be authentic.

4. Provide opportunities for visitors to express gratitude. We were pleasantly surprised by the expressions of thanks from visitors in surveys and like to think it gave them a boost, too. One study looked at the influence of requests for feedback on consumers' attitudes and behaviours. Findings showed that when companies start a survey by asking customers to recall positives about their experience, sales subsequently increased (Bone et al. 2017). How might these findings from market research be applied in a museum?

According to Brown, 'Embodying and practicing gratitude changes everything. It is not a personal construct - it's a human construct - a unifying part of our existence...' (Brown 2018: 83). As stated earlier, gratitude will not solve the challenges of a pandemic. Nor will it solve the difficulties of the civil, political, and economic unrest that have emerged since the pandemic's onset. Thanksgiving Point still faces daunting budget shortfalls, operational challenges, and the occasional less-than-happy visitor. But practising gratitude has created a sense of unity: we're facing challenges together and moving forward stronger and more resilient.

Received: 25 June 2020

Finally accepted: 23 July 2020 


\section{Notes}

1 For examples of blog posts and webinars related to self-care for museum professionals, see: Elizabeth Merritt, 'Questions and Suggestions from the Blackbaud Self-care Webinar', Center for the Future of Museums Blog, 2019. https://www.aam-us.org/2019/08/27/ questions-and-suggestions-from-the-blackbaud-self-care-webinar/, accessed 13 July 2020; Reggie Lynch and Meriel Stokoe, 'Seeking Self-Care Solutions, for COVID-19 and Beyond', American Alliance of Museums, 2020. https://www.aam-us.org/2020/04/24/ seeking-self-care-solutions-for-covid-19-and-beyond/, accessed 13 July 2020; Dan Yaeger, 'Museum Mindfulness \& Self-Care', 2020. https://www.youtube.com/watch?v=j820PecUw0, accessed 13 July 2020.

\section{References}

Bone, S.A., Lemon, K.N., Voorhees, C.M., Liljenquist, K.A., Fombelle, P.W., Detienne, K.B. and Money, R.B. (2017) '"Mere Measurement Plus": How Solicitation of OpenEnded Positive Feedback Influences Customer Purchase Behavior', Journal of Marketing Research, 54 (1) 156-70.

Brown, B. (2018) Dare to Lead: Brave Work. Tough Conversations. Whole Hearts, New York: Random House.

Jans-Beken, L., Jacobs, N., Janssens, M., Peeters, S., Reijnders, J., Lechner, L. and Lataster, J. (2019) 'Gratitude and Health: An Updated Review', The Journal of Positive Psychology, Advance online publication. https://doi.org/10.1080/17439760. $\underline{2019.1651888}$

Wong, Y.J., Owen, J., Gabana, N.T., Brown, J.W., Mclnnis, S., Toth, P. and Gilman, L. (2018) 'Does Gratitude Writing Improve the Mental Health of Psychotherapy Clients? Evidence from a Randomized Controlled Trial', Psychotherapy Research, 28 (2) 192-202.

\section{Author}

Kari Ross Nelson

ORCID iD: https://orcid.org/0000-0002-8012-2360

Research and Evaluation Associate

Department of Audience Research and Evaluation

Thanksgiving Point Institute

Utah

USA

kanelson@thanksgivingpoint.org 